\title{
Correction to: Novel metal complexes containing 6-methylpyridine-2-carboxylic acid as potent a-glucosidase inhibitor: synthesis, crystal structures, DFT calculations, and molecular docking
}

\author{
Davut Avcı $^{1}$ - Sümeyye Altürk ${ }^{1} \cdot$ Fatih Sönmez $^{2} \cdot$ Ömer Tamer $^{1} \cdot$ Adil Başoğlu $^{1} \cdot$ Yusuf Atalay $^{1} \cdot$ Belma Zengin Kurt $^{3}$. \\ Necmi Dege 4
}

Published online: 17 September 2021

C Springer Nature Switzerland AG 2021

\section{Correction to: Molecular Diversity (2021) 25:171-189 https://doi.org/10.1007/s11030-020-10037-x}

The authors regret that the project number was incorrectly given in the article. The authors would like to apologize for any inconvenience caused.

The corrected part is given below.

Acknowledgements This work was supported by the Scientific and Technological Research Council of Turkey (TÜBITTAK) (Project Number: MFAG-117F234) and the Scientific Research Projects Unit of Sakarya University (Project Number: 2018-1-6-67).
Publisher's Note Springer Nature remains neutral with regard to jurisdictional claims in published maps and institutional affiliations.

The original article can be found online at https://doi.org/10.1007/ s11030-020-10037-x

Davut Avc1

davci@sakarya.edu.tr

1 Department of Physics, Faculty of Arts and Sciences, Sakarya University, 54187 Sakarya, Turkey

2 Pamukova Vocational High School, Sakarya University of Applied Sciences, 54055 Sakarya, Turkey

3 Department of Pharmaceutical Chemistry, Faculty of Pharmacy, Bezmialem Vakif University, 34093 Istanbul, Turkey

4 Department of Physics, Faculty of Arts and Sciences, Ondokuz Mayıs University, 55139 Samsun, Turkey 